\section{Spanish jury defended}

SIR - As a member of the jury judging the merits of Maria Fernanda Sánchez for a research post as a palaeobotanist with the CSIC (the Spanish Council for Scientific Research), I should like to respond to her letter (Nature 363, 10; 1993).

(1) Sánchez applied for the post in December 1991 knowing she lacked validation of her doctorate from the University of Paris, which is a legal prerequisite.

(2) Nevertheless, on the occasion of the formal presentation (March 1992), the jury decided, because Sánchez was the only candidate, to try to overcome this legal deficiency. I suggested that we should ask the CSIC president whether there was some European legislation that might take precedence over the Spanish validation requirement or, alternatively, whether the jury might nevertheless proceed. This was because we felt that the Spanish requirement was out of step with those elsewhere in the European Communities and that this procedure would provide extra time for validation to take place. We were all anxious that the post should not be left empty, as we told Sánchez at the time.

We were shocked when the CSIC president replied unambiguously that validation of any foreign doctorate was necessary and that there was no European legislation to the contrary, but nevertheless urged us to continue with the examination of Sánchez for the post. Realizing that this would put us in an invidious position, three of us decided to resign when, in June 1992, Sánchez confirmed that her doctorate had still not been validated.

In retrospect it is clear that we were right to do as we did. First, an impeachment resulted from the appointment of a second palaeobotanist in similar circumstances in December 1991. Second, the new president of the CSIC recognized the inconsistency of his predecessor's arguments and cancelled the competition in November 1992.

I am sorry to have to say that $\mathrm{Dr}$ Sánchez has been unfair. I understand her disappointment and anger and her complaints about bureaucracy, but I cannot accept her accusations of complicity to hinder or delay the employment of Spanish researchers trained abroad. Indeed, I obtained my own first and second degrees at the University of California, Los Angeles, and the University of Copenhagen respectively.

As for references to the Franco regime, I consider these to be completely out of place and it is time to stop using them as an argument. Dr Sánchez may have been the victim of peculiar legislation or of bureaucracy, but, as she is perfectly aware, the jury was not in a position to behave any differently and did its best to help her. To state otherwise is to distort the truth.

\section{Arturo Morales Muñiz}

Universidad Autónoma Madrid,

Department of Biology,

E-28049Madrid, Spain

\section{Help wanted}

SIR - Two years have now passed since the great eruption of Mount Pinatubo in the Philippines, on 15 June 1991. It was one of the century's largest eruptions and many exciting new lessons have been learned from correlation of observed events, deposits and far-reaching atmospheric effects. Regrettably, we know very little about ash that fell in the South China Sea and South-East Asia, and this leaves considerable uncertainty about the total volume of magma erupted. Uncertainty about volume of erupted magma translates, in turn, into uncertainties about the volume and mechanisms of volatile release, of great interest to those studying the effects of volcanism on climate.

A plea in Nature for observations and samples shortly after the eruption of Krakatau in $1883(29,355 ; 1884)$ produced a wealth of information. With apologies for the lateness of this request, may we ask readers to contact either of us with any information about the time(s), thickness, mass per unit of surface area, grain size, mineral composition and other aspects of ash fall from the eruption? Samples with times and known collection area $\left(\mathrm{cm}^{2}\right)$ would be especially helpful.

Christopher Newhall

US Geological Survey,

Mail Stop 959,

Reston, Virginia 22092, USA

fax 1-703-648-6717

RaymundoS. Punongbayan

Philippine Institute of Volcanology and Seismology,

Hizon Building, 29 Quezon Avenue, Quezon City, Philippines

fax 63-2-711-3077

\section{Jurassic hype}

SIR - Henry Gee's review of Jurassic Park (Nature 363, 681; 1993) was enjoyable to read, but what is one tc make of his statement that "unless one looks too closely, there is nothing impossible about any of it in theory"? Since one cannot take both the caveat and the conclusion equally seriously, this is a formulation designed to have one's dinosaurs and pooh-pooh them, simultaneously.

As Nature remains a scientific maga- zine, it should be pointed out that there are at least two good scientific reasons, one genetic, one developmental, why the film's premise is, indeed, quite unsound.

Reason number 1: Dinosaurs, we may assume, suffered from some degree of genetic load as do all diploids. Given the fact that nonreplicating DNA suffers mutational pre-lesions with a rate proportional to time ${ }^{1}$, one may be fairly confident that any genome, no matter how intact, would have suffered one or more multiple lethal hits over 65 million or more years. A sufficiently old genome is bound to be a dead genome.

Reason number 2: the degree of match between cytoplasm and genome in an egg matters a great deal, in fact, even between relatively closely related species, let alone those differing by large taxonomic differences $^{2,3}$. If one wants successful dinosaur development, one had better use a good dinosaur genome - and not one randomly patched with frog DNA! - in a compatible, that is, dinosaur egg, cytoplasm. At present, there is no way to reconstruct the molecular composition of the latter.

I'm sure that the movie is terrific. It's a pity about the science.

Adam S. Wilkins

BioEssays

Company of Biologists, Ltd,

Austin Building, University of Cambridge,

New Museums Site, Pembroke Street,

Cambridge CB2 3ED, UK

1. Drake, J. W. in Evolution in the Microbial World (24th Symp. Soc. Gen. Microbiol., Cambridge University Press, 1974)

2. Wilson, A. C., Maxson, L. R. \& Sarich, V. M. Proc. natn Acad. Sci. U.S.A. 71, 2843-2847 (1974).

3. Elinson, R. P. Differentiation 9. 3-9 (1977).

\section{I have seen the} future ... .

SIR - It has been said that Great Britain and the United States are two countries separated by a common language. Further, the desire and frequent ability of Nature to be at, or even in advance of, the forefront is well known. A recent example simultaneously illustrating both of these phenomena appeared in your pages. On 14 June, while reading the issue of 10 June, I found the statement (page 491) that "... the great contaminated-blood trial is nearing its end, perhaps today (17 June)". Since this could not possibly be a typographic error, you have managed to illustrate a significant difference in the interpretation of temporal events on both sides of the Atlantic and, simultaneously, the uncanny ability of Nature to prognosticate.

\section{Frank L. Margolis}

Roche Institute of Molecular Biology,

340 Kingsland Street,

Nutley, New Jersey 07110-1199, USA 